\title{
Plan de Mercadotecnia para la Ruta del Cacao al Chocolate, en Tabasco, México
}

\author{
Fabiola Lizama Pérez \\ Universidad Tecnológica de Tabasco \\ María Lyssette Mazó Quevedo \\ Universidad Popular de la Chontalpa \\ Amisadai Díaz Montoya \\ Universidad Tecnológica de Tabasco
}

\section{Resumen}

La propuesta principal de la investigación se centra en la elaboración del plan de mercadotecnia para la Ruta del Cacao al Chocolate en el estado de Tabasco. En la primera parte del trabajo se presenta una evaluación del patrimonio cultural y natural de la zona turística en estudio; se inventariaron y jerarquizaron los recursos turísticos. En una segunda etapa se realizó una encuesta entre turistas en el periodo vacacional de julio y agosto 2012. Entre los hallazgos más importantes destaca que más de $80 \%$ considera que la mayor atracción es la zona arqueológica de Comalcalco, seguido de las playas del municipio de Paraíso y las haciendas cacaoteras. Asimismo, se realizó un análisis de la oferta, un análisis de la competencia y un análisis FoDA de la ruta. Para la elaboración del plan de mercadotecnia se consideró la vocación e identidad turística de la zona y los atractivos de mayor jerarquía turística. Para potenciar la demanda se utilizó un sitio web para difundir la ruta y los atractivos turísticos.

\section{Palabras clave}

Plan de mercadotecnia, turismo, sitio web. 


\title{
Marketing Plan for the Cocoa to Chocolate Route in Tabasco, Mexico
}

\begin{abstract}
Abstrac
The first section of this research shows a study of the natural and cultural heritage of the "cocoa-chocolate route" where we can find : farms involved in the cocoa production and chocolate processing, the Archaeological site of Comalcalco, Catholic temples in Chontal communities of Tucta, Mazateupa and Oxiacaque.Furthermore, the tour includes a visit to the beaches of Paraiso, Puerto Ceiba, PomposuJuliva wetlands and the lagoon of Mecoacan, among other natural attractions. The second section consists on a survey of tourists who visited touristic places on holidays from July to August 2012. The results revealed that more than $80 \%$ of the tourists consider that the greatest attractions on the "cocoa-chocolate route" are : the Archaeological site of Comalcalco, the beaches in Paraiso and the chocolate farms. In addition, there is an analysis on supply and demand, competence and FODA focused on the "cocoa-chocolate route".Considering the previous stages of this research, there was a selection of strategic touristic resources which would be the basis for the development of a "cocoa-chocolate route" plan. This plan designed several strategies such as the use of advertising campaigns in mass media, like the radio, TV, posters and brochures. Finally, it was determined to foster the touristic demand using a website to advertise the route and its attractions to be marketed, as well as to highlight the image of the route in order to benefit the State and the towns comprised on the route. As a result, this would lead to increase the economic profit and promote the State sustainability.
\end{abstract}

KEY WORDS

Plan of marketing, tourisim, website.

102 Correo electrónico: flizamap@ hotmail.com 


\section{Introducción}

De la Torre Padilla, en su libro Turismo, fenómeno social, define de manera objetiva el concepto de turismo como un fenómeno social que consiste en el desplazamiento voluntario y temporal de individuos o grupos de personas que, fundamentalmente con motivo de recreación, descanso, cultura o salud, se trasladan de su lugar de residencia habitual a otro, en el que no ejercen ninguna actividad lucrativa ni remunerada, generando múltiples interrelaciones de importancia social, económica y cultural (1980). El congreso Interamericano de Turismo considera que el turismo es una fuerza cultural, económica y social cuyo impacto en todos los sectores de la sociedad es reconocido universalmente, ya que pone en contacto personas de formación y niveles de vida diferentes, estrechando relaciones, rechazando prejuicios y anulando arrogancias, siendo el turista un embajador de la cultura de su país quien a su vez asimila la cultura con la cual entra en contacto (Cárdenas, 1986). El turismo es un fenómeno social que trasciende de otro fenómeno social: el tiempo libre institucionalizado. Es decir, el turismo como fenómeno tiene esencia (el ocio) y un conjunto de manifestaciones que se interrelacionan e interactúan. Estas manifestaciones son de orden ideológico, político, económico, social, psicológico y físico-ambiental (Boullón, 1983). Uno de los segmentos del turismo de naturaleza es el ecoturismo:

aquella modalidad turística ambientalmente responsable, consistente en viajar o visitar áreas naturales relativamente sin disturbar con el fin de disfrutar, apreciar y estudiar los atractivos naturales de dichas áreas, así como cualquier manifestación cultural a través de un proceso que promueve la conservación, tiene bajo impacto ambiental y cultural y propicia un involucramiento activo y socioeconómico beneficioso de las poblaciones locales [Acerenza, 2006].

Otro segmento es el turismo rural: "Viajes que tienen como fin realizar actividades de convivencia e interacción con una comunidad rural, en todas aquellas expresiones sociales, culturales y productivas cotidianas de la misma” (Secretaría de Turismo de México, 2004). 
Un destino puede identificar su mercado objetivo apropiado de dos formas: la primera consiste en recabar información acerca de sus visitantes actuales. De dónde vienen y por qué. Cuáles son sus características demográficas. Si están satisfechos y cuánto. Cuántos han venido antes. Cuánto gastan. Examinadas éstas y otras preguntas, los planificadores pueden decidir a qué tipo de turistas dirigirse. La segunda consiste en hacer un inventario de atracciones que ofrece el destino y seleccionar aquellos segmentos que lógicamente puedan estar interesados (Kotler, 2004). Segmentar un mercado turístico es dividir el mercado potencial total en un número de subconjuntos lo más homogéneos posible, con el fin de permitir a los operadores del turismo adaptar políticas de comercialización a cada uno de esos segmentos o subconjuntos (Cárdenas, 1997).

De acuerdo con Goeldner (2011) el plan de mercadotecnia para un destino o empresa es uno de los documentos de trabajo más importantes. Sirven para traducir los numerosos ideales de las políticas públicas del turismo en un proceso activo para atraer visitantes y proporcionar la variedad de experiencias que buscan de un destino. El plan de mercadotecnia debe integrar estrategias que direccionen el desarrollo de los proyectos. La estrategia es el planteamiento general sobre la forma como se debe conducir un hecho o actividad, a fin de que alcance satisfactoriamente los objetivos que se le han fijado y se aproxime por lo tanto a la "situación deseada". Es un proceso de planificación, pocas veces puede adaptarse una estrategia sin antes haber analizado y evaluado varias alternativas, ya que esta etapa es crucial para el éxito o fracaso del proceso (Hernández, 2005).

\section{Antecedentes}

El presente trabajo se deriva del proyecto de investigación financiado por Promep denominado Plan estratégico para el desarrollo turístico sustentable de los municipios de Comalcalco, Paraíso, Cunduacán, Jalpa de Méndez y Nacajuca, destinos integrantes de la Ruta del Cacao al Chocolate.

De acuerdo con datos proporcionados por la Secretaría de Turismo del estado de Tabasco el porcentaje de ocupación hotelera es de $54.11 \%$, con un 
promedio de estadía de 2.05 noches. Además, existe poca atención al turismo recreativo, ecológico, cultural y de aventura; se advierte la carencia de capital humano calificado en el área y falta de promoción a nivel nacional e internacional de los eventos culturales. Desde su establecimiento en el año 2004, la Ruta del Cacao al Chocolate ( $\mathrm{RCCH}$ ) ha procurado una imagen diferenciada entre las siete rutas turísticas de Tabasco. Integrada por cinco municipios: Comalcalco, Cunduacán, Paraíso, Jalpa de Méndez y Nacajuca; la ruta ofrece una variedad de atractivos, primordialmente culturales. De esta manera, la ruta se caracteriza por su capacidad en infraestructura y equipamiento turístico, posicionándose como la segunda más visitada en Tabasco, después de la Ruta Villahermosa. En contraste, es notable que pese al impulso que se ha otorgado para fortalecer su funcionamiento, en la ruta existen problemas que limitan su integración, lo cual incide en su competitividad, es decir, los productos turísticos aún se encuentran en fase incipiente y se detectan falta de alianzas estratégicas entre los prestadores de servicios turísticos con la finalidad de integrar la oferta turística a través de paquetes promocionales. Se presume lo anterior por la falta de investigaciones de mercado para la oportuna comercialización de los productos turísticos que se ofrecen en la zona.

\section{Metodología}

El presente proyecto de investigación se realizó en tres etapas.

Etapa 1. Evaluación del patrimonio natural y cultural de la Ruta del Cacao al Chocolate (RCCH)

- Elaboración del inventario turístico

- Jerarquización de los atractivos turísticos

- Evaluación de la Ruta del Cacao al Chocolate

\section{ETAPA 2. ANÁLISIS DE MERCADO}

- Análisis de la demanda

- Análisis de la oferta turística

- Análisis de la competencia

Análisis FODA 


\section{ETAPA 3. Plan De MERCADOTECNIA}

- Productos turísticos

- Elaboración de estrategias y fijación de objetivos

- Plan de medios

El primer paso para la evaluación del patrimonio consiste en inventariar todos los atractivos naturales y culturales que se incluyen dentro del área de estudio y hacer referencia a todos aquellos lugares, objetos y acontecimientos capaces de atraer a personas, y que son motivo suficiente para emprender un viaje, y que como lo mencionan las definiciones tradicionales son parte del patrimonio turístico de un país, junto con la planta y la infraestructura turísticas tanto públicas como privadas (Zamorano 2007).

Dentro del estudio del entorno físico de los proyectos turísticos se encuentra el denominado inventario turístico, que se debe determinar a partir de la relación de atractivos turísticos, planta turística, infraestructura y superestructura turística. En ocasiones se utiliza el término recursos y se dice, por tanto, inventario de recursos turísticos, aunque es más aconsejable emplear la palabra patrimonio; así, se dice inventario del patrimonio turístico (Cárdenas, 2006).

\section{Resultados}

La elaboración del inventario implica el registro de la información en cédulas de recursos naturales y culturales. Para el registro material de la información es indispensable dedicar a cada atractivo una ficha que contenga todos los datos necesarios para su identificación, a saber: nombre, categoría, tipo o subtipo, jerarquía, localización, medios de acceso, número aproximado de visitantes, y épocas del año de mayor concurrencia. Características que le confieren interés turístico. El segundo paso para la evaluación del patrimonio consiste en la jerarquización del patrimonio natural y cultural, de acuerdo con sus características y al grado de atracción que ejercen sobre los turistas. Según Cárdenas (2006) la jerarquización se establece de cinco a cero. Una vez asignada a cada atractivo turístico su jerarquía, se realiza la suma de los puntos correspondientes a las 
Cuadro 1. Ubicación geográfica de los municipios que integran la Ruta del Cacao al Chocolate

\section{Comalcalco}

Su nombre náhuatl, coma-cali-co, quiere decir "la casa de los ladrillos como comales". Su extensión es de 723.19 km² y tiene una población es 156334 habitantes. Sus ríos son Cuxcuchapa, Seco y Tular. El clima es cálido húmedo con abundantes lluvias en verano. Produce cacao, coco, frijol, pimienta, frutales, ganado bovino y porcino. Sus actividades industriales son petrolera, transformación del coco y fabricación de chocolate; las actividades comerciales son importantes. Aquí se localiza el museo de sitio de la zona arqueológica de Comalcalco.

\section{NACAjuca}

En náhuatl, naca xu-xu-ca, significa "lugar de las carnes pálidas o descoloridas"; su población es de 68149 habitantes; su territorio tiene $452.33 \mathrm{~km}^{2}$ y pertenece a la llanura costera. El clima es cálido húmedo con abundantes lluvias en verano. Sus ríos más importantes son Nacajuca, González, San Cipriano, Naranjo y Mango. Sus lagunas son Cantemoc, Bayasu, Bush, Juliva, Horizonte, Manguito y Tintalito. Produce maíz, frijol y cítricos; ganado bovino, porcino y aves. La pesca de bobo, robalo, pejelagarto y mojarra se realiza para el autoconsumo. El ramo de la industria tiene baja producción, sobresalen los talleres de artesanías hechas con caña y palmas, como abanicos, petates, sombreros, bolsas tejidas; elaboran también tiras bordadas y tambores, la mayoría de ellos se ubican en poblados indígenas chontales. En Saloya turísticamente se concentra la gastronomía estatal más típica y exquisita en lo que al pescado y mariscos se refiere.

\section{CUNDUACÁN}

Su nombre náhuatl, comiti-ua-can, significa "lugar de ollas". Ocupa una extensión de 623.09 km2 y su población es de 97698 habitantes. Sus ríos son Mezcalapa, Samari, Cucuxchapa y Seco; sus lagunas, Cucuyulapa y Ballona. El clima es cálido húmedo con abundantes lluvias en verano. Produce cacao, plátano y árboles maderables como cedro, caoba y tatúan; ganado bovino, porcino y aves. Se produce petróleo y allí se localiza el sitio de la batalla del Jahuactale e importantes murales históricos. 


\section{JaLPA DE MÉNDEZ}

Su nombre náhuatl, sha-pan o allí-pan, quiere decir "lugar sobre arena". Tiene 64282 y cuenta con $375.67 \mathrm{~km}^{2}$ de extensión territorial que pertenece a la llanura costera. EL clima es cálido húmedo con abundantes lluvias en verano. Sus ríos son Cuxcuchapa y Chacalapa; y sus lagunas, Pomposú y el Eslabón. Se produce maíz, frijol, cacao y futales; la pesca y la ganadería son escasas; en la industria destaca el campo petrolero Mecoacán, sin embargo, sobresalen en artesanías las jícaras labradas. La ciudad de Jalpa de Méndez es la cabecera municipal; lleva el nombre de Méndez en honor del coronel Gregorio Méndez Magaña, nativo de este lugar. Destacan en el municipio la casa museo Coronel Gregorio.

\section{PARAÍSO}

Se cree que su nombre se debe a lo exuberante de su vegetación y su fauna, o a que fue fundado en el antiguo paso del paraíso, donde existen árboles con este nombre. Tiene una superficie de $377.55 \mathrm{~km}^{2}$. Cuenta con una población de 65266 habitantes. Sus ríos son Seco, González y Cuxcuchapa; sus lagunas, Mecoacán, Tupilco y Arrastradero, y Barras de Chiltepec, Dos bocas y Tupilco. El clima es cálido húmedo con abundantes lluvias en verano. La producción de petróleo ha disminuido, así como la pesca y la producción de coco. El puerto de altura de Dos bocas da salida a productos petroleros hacia el país y el extranjero. Sus principales centros turísticos son el Bellote, Puerto Ceiba, balnearios el Paraíso y Varadero, entre otros.

Fuente: García, 2000.

diferentes jerarquizaciones para establecer la calidad de los atractivos que se encuentran en la ruta turística. A partir de 56 puntos en adelante la calidad es buena, y se puede fomentar el turismo receptivo para obtener divisas que hagan más rentables los proyectos turísticos.

La Secretaría de Turismo estatal ha promovido la integración de siete rutas turísticas, entre ellas la RCCH, que incluye la visita a cinco municipios de Tabasco, que se encuentran en la subregión de la Chontalpa. En el cuadro 1 se 
describen las características generales de los municipios que integran la Ruta del Cacao al Chocolate.

\section{Etapa 1. Evaluación del patrimonio natural y cultural de la Ruta del Cacao al Chocolate (RсCH)}

El patrimonio cultural tangible e intangible es el elemento central de la identidad y la soberanía de una nación; por medio de él es posible conocer la evolución de los valores sociales, económicos, políticos, artísticos, arquitectónicos, etc., que cada pueblo ha tenido a lo largo de su historia y, por tanto, debe ser prioridad en las políticas sociales de cada país (Sánchez, 2007). Los atractivos naturales y culturales que se evaluaron pertenecen a los cinco municipios descritos. En el trabajo de campo se procedió al levantamiento del inventario turístico a través del llenado de las cédulas de recursos naturales y culturales, posteriormente se jerarquizó cada uno de ellos, con la participación de autoridades municipales, académicos expertos en el área, prestadores de servicios turísticos y líderes municipales de la RCCH. Finalmente, se realizó la suma del puntaje de cada uno de los atractivos que integran la ruta en estudio, lo que en su conjunto ganó una valoración de 65 puntos, considerándose en la categoría de calidad turística buena y conjugando un producto turístico consolidado con una diversidad de atractivos tanto culturales como naturales.

\section{Iglesias polícromas de la Chontalpa, Tabasco}

Las iglesias polícromas se sitúan principalmente en los municipios de Nacajuca, Jalpa de Méndez y Comalcalco, en la región de la Chontalpa. Los templos del siglo xvir consistían en una construcción cuyo diseño era igual al de las viviendas indígenas, aunque con un techo más elevado. En su interior se observaban imágenes rústicas de santos de piel morena, junto con instrumentos musicales, máscaras y pelucas utilizados por los indígenas en sus ceremonias religiosas. Los templos católicos de esta región -en la que reside sobre todo la etnia yokot'an-, han estado íntimamente relacionados con las comunidades. El templo más antiguo de la RCCH es la iglesia de las Mirandillas del siglo xviII, en 

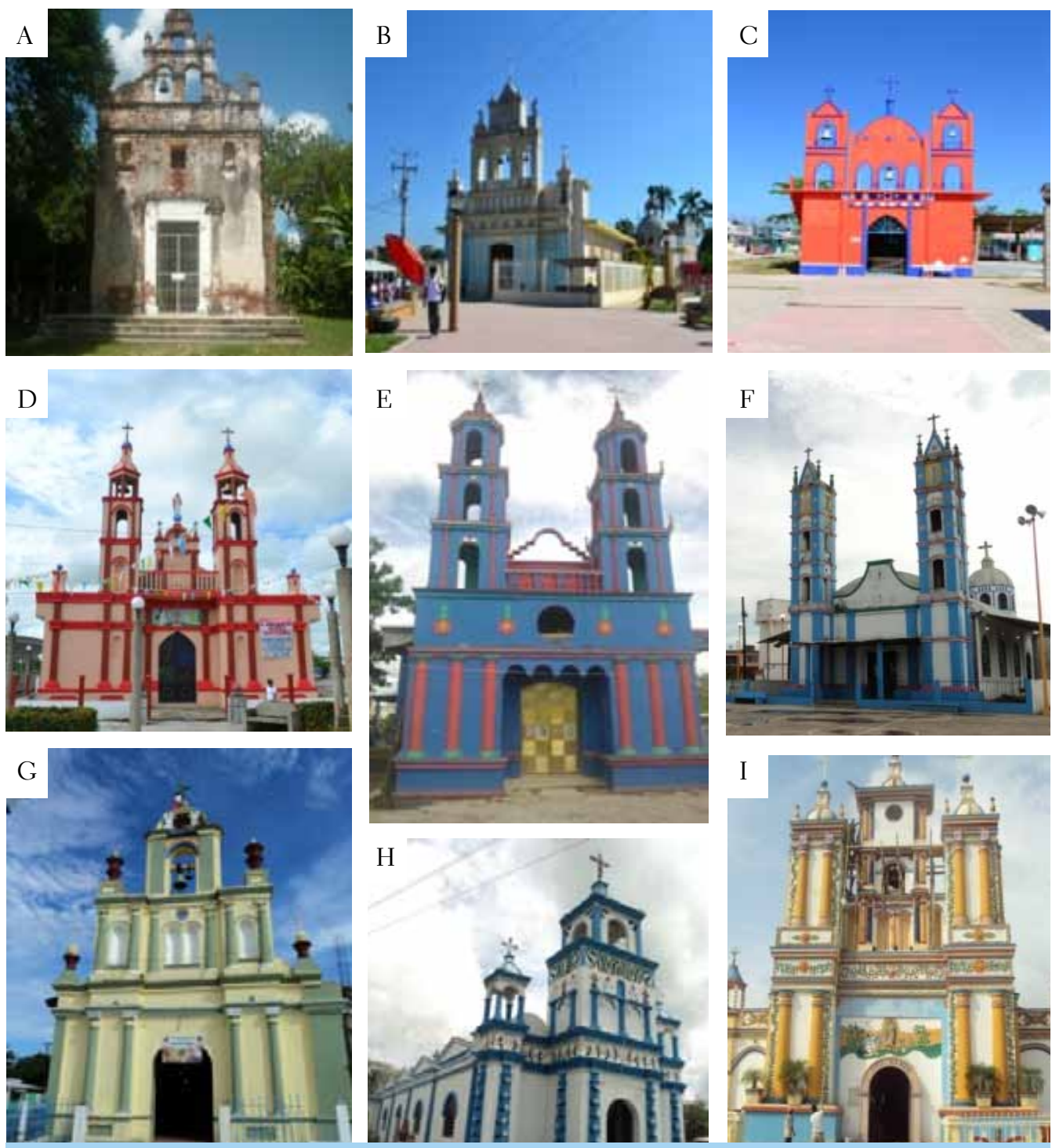

Figura 1. Iglesias polícromas de la Chontalpa, Tabasco

A. Templo de las Mirandillas en Cunduacán, B. Templo de San Marcos en Guatacalca, Nacajuca, C. Templo de la Virgen de la Asunción en Oxiacaque, Nacajuca, D. Templo de la Virgen del Carmen en Tapotzingo, Nacajuca, E. Templo de San Pedro y San Pablo en Guaytalpa, Nacajuca, F. Templo de Santiago Apóstol en Tucta, Nacajuca, G. Templo de San Lázaro en Mazateupa, Nacajuca, H. Templo de San Isidro Labrador, en San Isidro, Nacajuca, I. Templo de Cupilco, Comalcalco

Fuente: Trabajo de campo. Fotos: Archivo personal. 
el municipio de Cunduacán. A pesar de la riqueza cultural de los pueblos de la Chontalpa, en donde se encuentran enclavados estos templos, no se registra una actividad turística importante; los visitantes de estos pueblos son por lo regular personas de los municipios cercanos que asisten a las ceremonias religiosas y fiestas tradicionales. La jerarquía alcanzada es de dos puntos. A excepción de Cupilco que es el templo de mayor atracción para turistas, el cual alcanza la jerarquía tres (véase figura 1).

\section{Zona arqueológica de Comalcalco}

Este centro político-religioso se construyó entre el año 100 a. de C. y el 900 de nuestra era. Fue quizá la capital de una ciudad-Estado relativamente grande y compacta de la región de los chontales o Chontalpa; se considera que este sitio ejerció fuerte influencia en Campeche, la zona del Golfo y en Pomoná, a través del uso de ladrillos estilo Comalcalco (grabados y luego cocidos en hornos abiertos), los cuales aparecen en las ofrendas o como elementos decorativos en algunos edificios y en las vasijas de cerámica. Sus principales actividades fueron la agricultura, el comercio, la pintura, la cerámica y el modelado. Entre las obras de construcción más importantes de Comalcalco se encuentran los edificios construidos con ladrillos de barro cocido, unidos con una mezcla de arena, cal y conchas de ostión, de los que sobresalen tres conjuntos arquitectónicos la Plaza Norte, la Gran Acrópolis y la Acrópolis del Este (García, 2000).
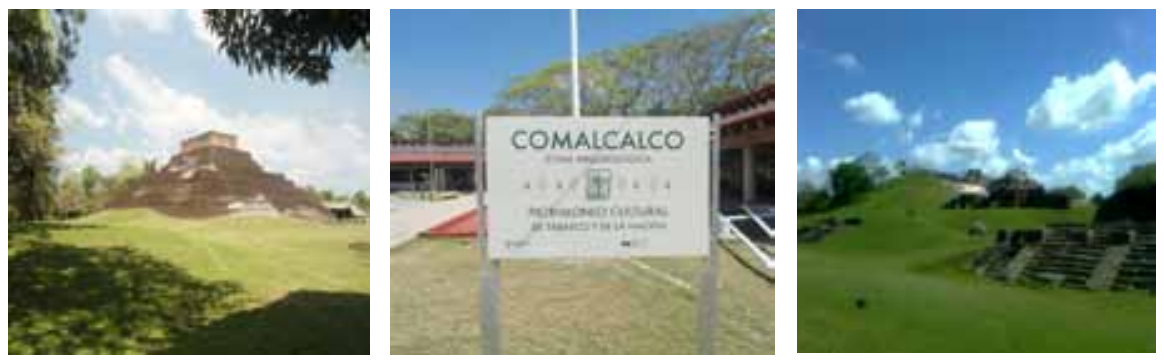

Fuente: Trabajo de campo. Fotos: Archivo personal.

Figura 2. Zona arqueológica de Comalcalco 
Está plenamente demostrado que las zonas arqueológicas son un gran atractivo para el turismo, con la consecuente derrama económica a la localidad, dando al visitante la oportunidad de apreciar cómo eran las costumbres y formas de vivir de las diversas culturas de la región (Torruco, 1999). En Comalcalco, además de observar sus pirámides, como las que se muestran en figura 2, podemos apreciar el decorado con el que los mayas embellecieron algunos de los ladrillos que elaboraron para edificar sus construcciones, así como las esculturas en relieve que se localiza en las paredes de los edificios. Esta zona arqueológica es la más visitada en el estado de Tabasco. El $72 \%$ de los visitantes son turistas nacionales y $28 \%$ turistas extranjeros. Se le asignó una jerarquía de cuatro por ser un atractivo con rasgos excepcionales en el país, capaz de motivar una corriente (actual o potencial) de visitantes del mercado interno o externo ya sea por sí solo o en conjunto con otros atractivos cercanos.

\section{Artesanías}

Las artesanías han recorrido un largo trayecto histórico. Son, desde hace siglos, manifestaciones culturales y económicas de las poblaciones indígenas y mestizas; elaboradas con técnicas sencillas y tradicionales, empleando los materiales que ofrece el medio donde se ubica el grupo que los elabora. (Casasola, 1990). Las artesanías son resultado del trabajo manual de hombres y mujeres, que cuidadosamente van moldeando, tejiendo o labrando las materias primas, hasta concluir

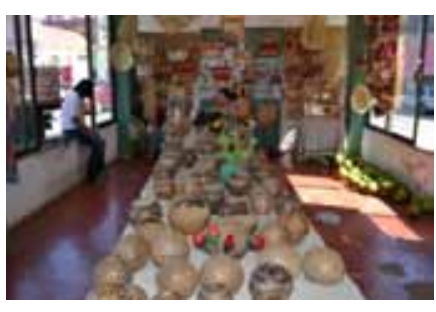

A. Asociación de artesanos de Jalpa de Méndez

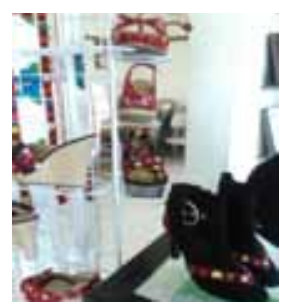

B. Artesanías tiras bordadas

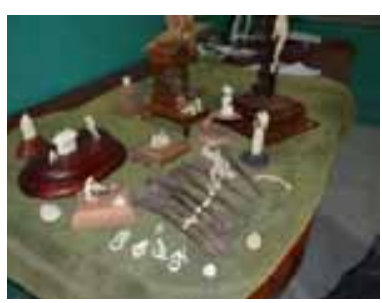

C. Artesanías de la madera y el hueso

112 Fuente: Trabajo de campo. Fotos: Archivo personal.

Figura 3. Artesanías 
con satisfacción un producto útil y agradable a la vista, surgieron para contribuir a satisfacer las necesidades del hombre, por ello su origen es muy antiguo (Azcona, 2010). Las artesanías típicas se elaboran con material de guano redondo, el jícaro, la cañita y el Jacinto. Con el guano se elabora el sombrero chontal, cestos, escobas, bolsas y abanicos. Los petates se elaboran de la cañita. La fibra del Jacinto se transforma en bolsas y cubreasientos. También se elabora la tira bordada, que sirve para decorar blusas, toallas, fundas, sábanas, manteles y servilletas. Una artesanía muy apreciada es la elaborada a base de la madera y el hueso. Sin embargo y a pesar de la belleza de estas artesanías, no son capaces por sí solas de motivar un viaje de turistas, por lo que se les asignó la categoría dos.

\section{Haciendas cacaoteras}

En los años treinta la hacienda La Luz fue adquirida por un inmigrante alemán, el Dr. Otto WolterHayer, convirtiéndola en una de las primeras fincas cacaoteras de la región de la Chontalpa tabasqueña. En 1958, el hacendado Wolter, fundó en la hacienda una fábrica de chocolates caseros que ha seguido sus actividades hasta la fecha. En el jardín exterior se puede admirar árboles y plantas típicas de la región (algunas en peligro de extinción) y plantas exóticas, cuyas variedades conforman un jardín botánico. Dentro de la hacienda se encuentra el Museo del Cacao y Chocolate Dr. Otto Wolter Hayer, que se inauguró en noviembre del 2003. La hacienda Jesús María cuenta con una extensión de 60 hectáreas. La historia cuenta que cuando don Rutilo Peralta adquirió esta propiedad en 1930, ya era una hacienda cacaotera. En 1970 pasa a ser de su nieto Juan Cacep Peralta, quien inicia el proceso y molienda del cacao de forma de pasta. Poco a poco se convirtió en una de las haciendas con mayor producción de chocolate, ya que cuenta con la maquinaria adecuada. Al lado de la casa, se encuentra el invernadero donde hay plantas de cacao criollo que se usan para su reproducción a través de injertos. En la antigua casona, se puede admirar una cocina chontal. En el siglo xix, los dueños de la finca Cholula eran sacerdotes franciscanos, provenientes de Cholula, Puebla. Luego la vendieron a los padres de don Juan Riveroll Somellera, quien empezó con el cultivo de cacao. En 1948 comienzan con la venta de este producto de manera formal y elaboración rústica; y hace unos años abrieron la finca al 
público para dar a conocer un poco de su historia y los proyectos que tienen en pro de la ecología. En la finca existe una gran diversidad de plantas exóticas en diferentes tonalidades, muchas de ellas curativas y en peligro de extinción. Detrás de la casona se encuentra la fábrica de chocolate; al lado, los viveros de cacao, los cuales son un proyecto para conservar los recursos naturales del ecosistema cacaotal, que llevan a cabo con la ayuda de financiamientos de diferentes programas.

Las haciendas cacaoteras obtuvieron una jerarquía de tres, por ser atractivos con algún rasgo llamativo capaz de interesar a visitantes de larga distancia, ya sea del mercado interno o externo, que hubiesen llegado a la zona por otras motivaciones turísticas o por motivar corrientes turísticas locales (actuales y potenciales).
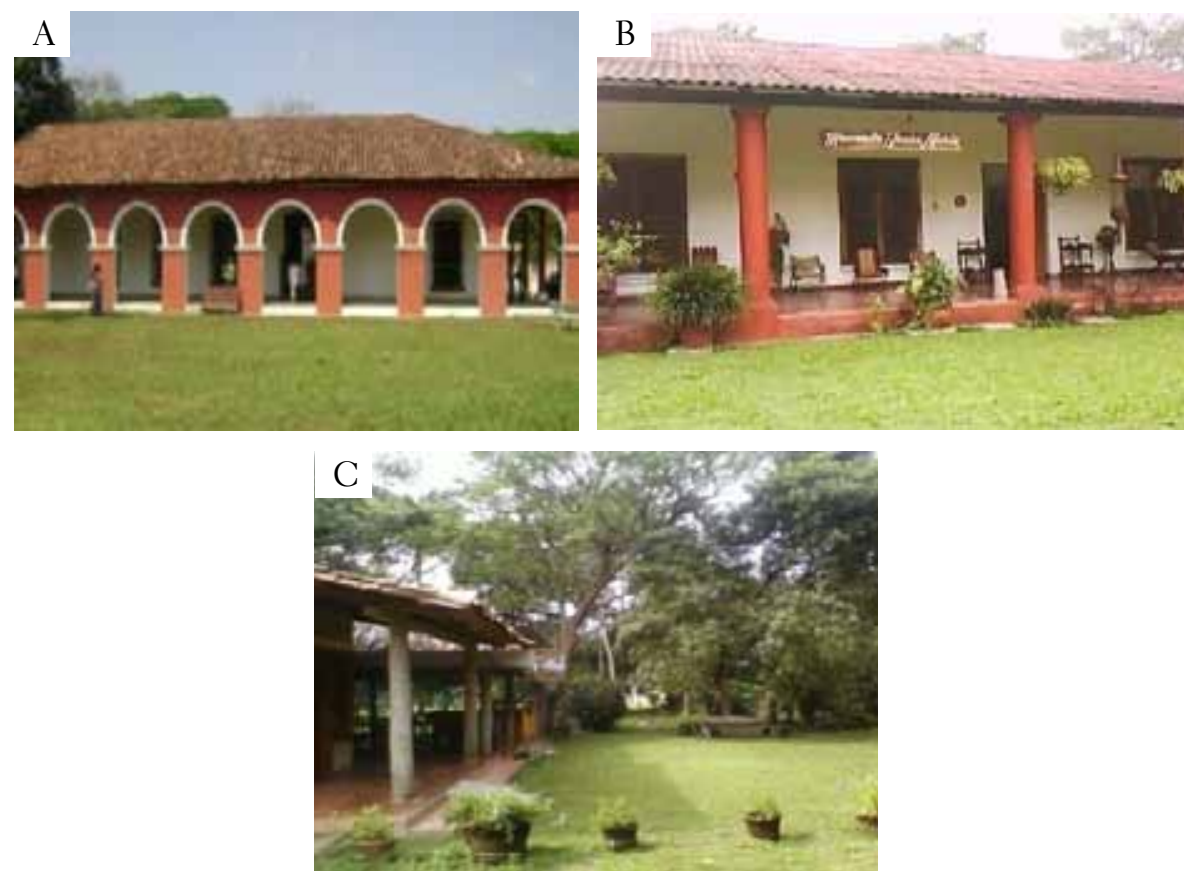

A. Hacienda la Luz, B. Hacienda Jesús María, C. Finca Cholula

114 Fuente: Trabajo de campo. Fotos: Archivo personal.

Figura 4. Haciendas de Comalcalco 


\section{Evaluación del patrimonio natural}

La RCCH cuenta con áreas de admirable belleza paisajística, como playas, humedales, ríos, lagunas, barras y esteros. Además se han implementado proyectos como granjas de tortugas y cocodrilos, que hacen del patrimonio natural uno de los más agradables del estado de Tabasco y de México. Estas maravillas naturales son posibles debido a que la mayor parte de nuestro estado lo conforman terrenos planos, y en la descarga de las aguas de los ríos al mar se forman importantes sistemas lagunares.
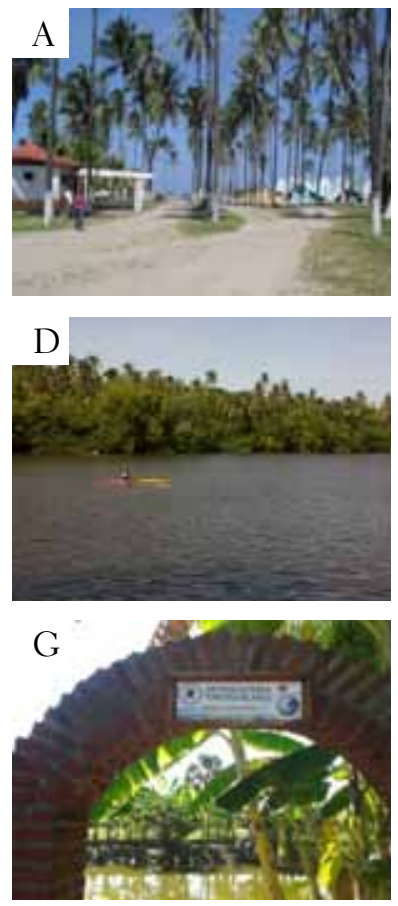
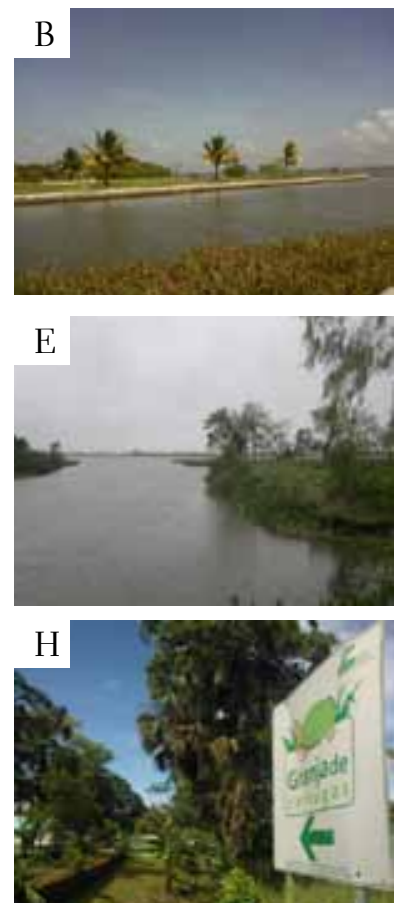
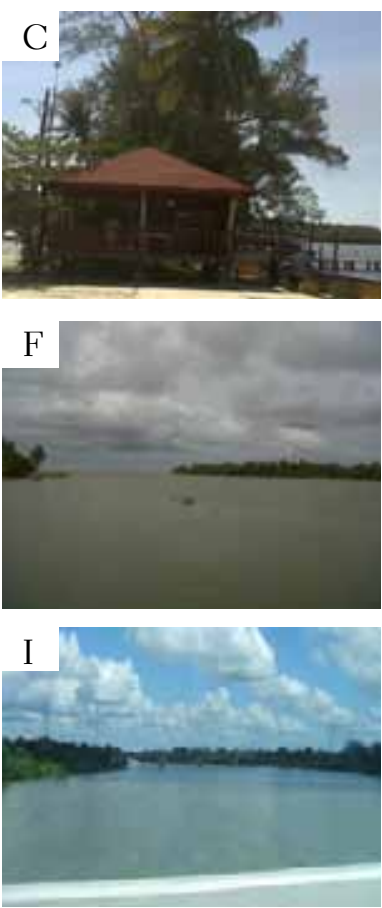

A. Playas de Paraíso, B. República Paraíso, Paraíso, C. Puerto Ceiba, Paraíso, Paraíso, D. Laguna de Mecoacán, Paraíso, E. Humedales de Pomposú, Julivá, Jalpa de Méndez, F.Chiltepec, Paraíso, G. Granja de tortugas. La Encantada, Jalpa de Méndez, H. Granja de Tortugas UMMA, Nacajuca, I. Río Samaria, Cunduacán.

Fuente: Trabajo de campo. Fotos: Archivo personal.

Figura 5. Patrimonio natural de la Ruta del Cacao al Chocolate 
Las características geográficas de la Ruta del Cacao al Chocolate han permitido la formación de los ecosistemas que conforman el patrimonio natural. Estos atractivos han alcanzado la jerarquía tres por ser atractivos con rasgos llamativos capaces de interesar a visitantes de larga distancia, ya sea del mercado interno o externo, que hubiesen llegado a la zona por otras motivaciones turísticas o de motivar corrientes turísticas locales actuales y potenciales. Estos atractivos son muy demandados actualmente, por lo que se requiere implementar proyectos de conservación del patrimonio natural basados en los criterios de desarrollo sustentable, cuya implementación está siendo insistentemente promovida por organizaciones internacionales y adoptada por algunos gobiernos, pues sus postulados, programas y acciones se recogen en la obra Cuidar la Tierra, estrategia para el futuro de la vida (Molina, 1998).

\section{Etapa 2. Investigación de mercados}

\section{Análisis de la demanda}

En una segunda etapa se realizó un estudio de mercado en el periodo vacacional de julio y agosto 2012, en donde se halla un análisis de los resultados de una encuesta aplicada entre turistas que visitaron los atractivos turísticos de la RCCH. Las entrevistas se efectuaron, asimismo, en diferentes atractivos de la ruta y en distintos horarios de mañana y tarde, para tratar de recoger el abanico más amplio de personas y situaciones. Para la selección de los entrevistados no se estratificó ni por sexo, edad, nacionalidad ni por ninguna otra variable, siendo el procedimiento la selección de aquellos turistas que aparecían y que estaban dispuestos a contestar en un intervalo de unos diez minutos. La tasa de rechazo fue muy baja y no significativa en función de variable alguna.

\section{Proceso utilizado para determinar el tamaño de la muestra}

Se utilizó la información proporcionada por la Secretaría de Turismo acerca de la afluencia de turistas nacionales y extranjeros en el periodo enero-diciembre 2011. 


$$
n=\frac{N_{o}{ }^{2} Z^{2}}{e^{2}(N-1)+o^{2} Z^{2}}
$$

Donde 384 fue el tamaño de la muestra.

Principales hallazgos de la encuesta aplicada a los turistas

a) Medio por el cual el turista se enteró de los atractivos turísticos

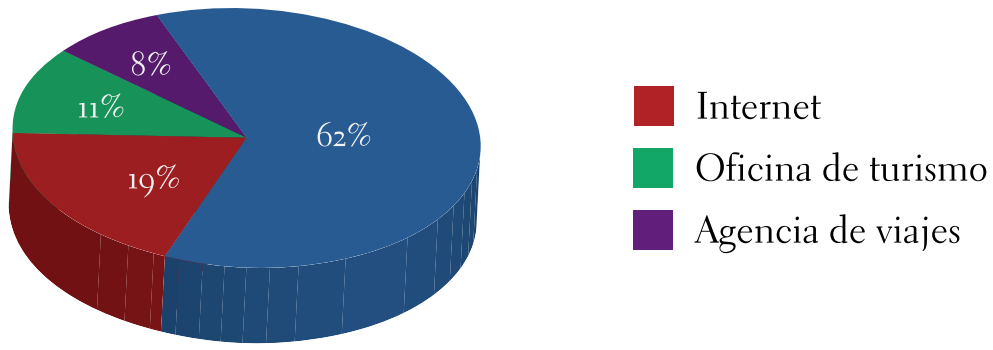

Figura 6. Medio por el cual se enteró el turista de la Ruta del Cacao al Chocolate

b) Origen de los turistas que visitan la ruta. En cuanto a la procedencia extranjera, los turistas que visitan la RccH provienen de Argentina, Cuba y Estados Unidos, principalmente, en una proporción de $0.8 \%$ de cada uno de estos países. El turismo nacional viaja de Jalisco (7.3\%), Veracruz (4.7\%) y en mayor medida de Chiapas (8.1\%).

c) Ocupación de los turistas
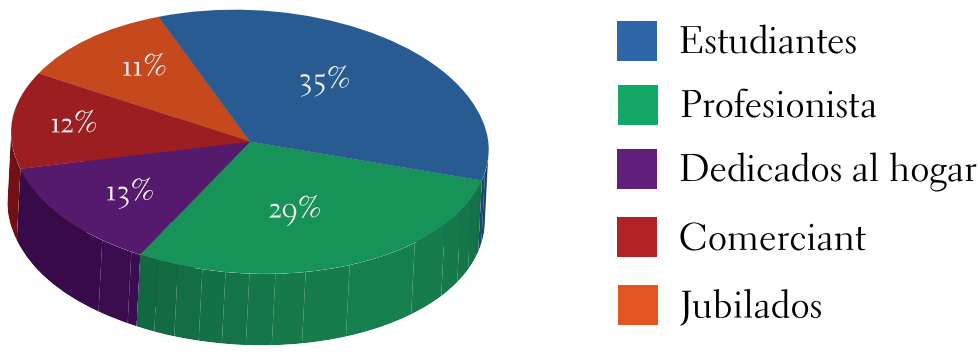

Figura 7. Ocupación de los turistas 
d) Establecimiento que los turistas prefieren para hospedarse en la región

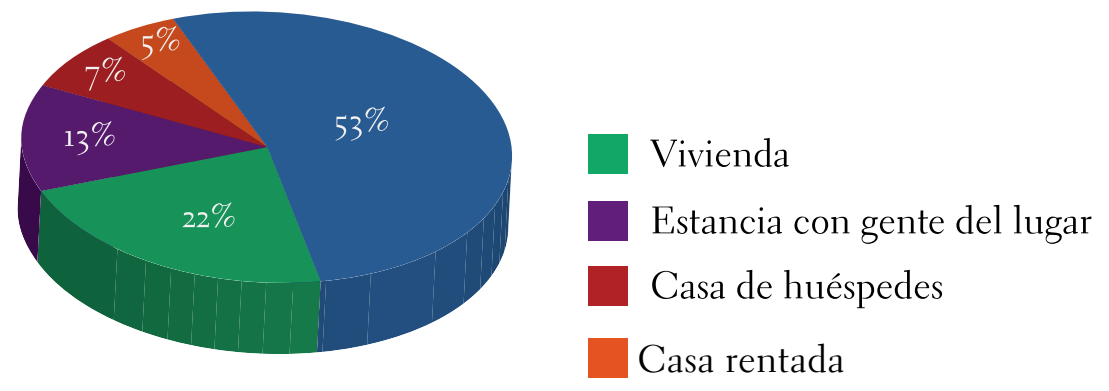

Figura 8. Tipo de hospedaje elegido por los turistas

e) Motivo por el cual los turistas visitan la Ruta

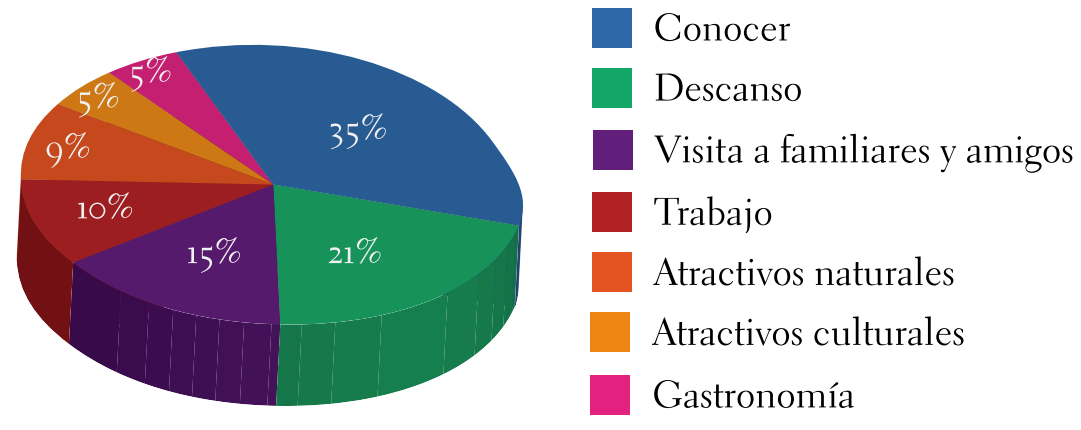

Figura 9 Motivo del recorrido de la Ruta del Cacao al Chocolate

f) Máxima atracción de la Ruta del Cacao al Chocolate

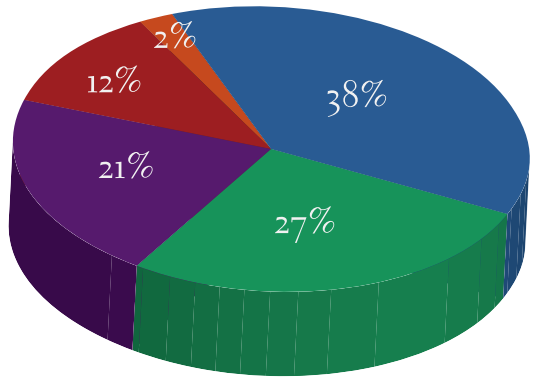

Zona arqueológica Comalcalco

Playas de paraíso

Haciendas chocolateras

Puerto Ceiba

Iglesia de Cupilco

Figura 1o. Principal atracción de la Ruta del Cacao al Chocolate 
Más de $80 \%$ de los turistas consideran que la mayor atracción de la RCcH está en la zona arqueológica de Comalcalco, las playas del municipio de Paraíso y las haciendas chocolateras.

En los análisis de los resultados de la encuesta también se encontraron algunos datos interesantes con respecto al porcentaje de turistas totalmente satisfechos. En el cuadro 2 se presentan algunos datos recabados.

Cuadro 2. Satisfacción del turismo con respecto a los servicios proporcionados en la RCCH

\begin{tabular}{l|c} 
Rubro & Turistas satisfechos (\%) \\
Por la atención del personal & 28 \\
Visita a los sitios históricos-culturales & 31 \\
Calidad de las artesanías & 33 \\
Instalaciones de los establecimientos de hospedaje. & 29 \\
Servicio de los establecimientos de hospedaje de la RCCH & 32 \\
Seguridad del destino & 30 \\
Servicio de alimentos y bebidas & 36 \\
Limpieza de los sitios turísticos & 31 \\
Actividades que se pueden realizar & 14 \\
Calidad de las actividades & 17 \\
Información disponible acerca de los lugares y actividades que & 26 \\
se pueden realizar en la RCCH & 20 \\
Señalización del destino (RCCH) & 25 \\
Servicios de gasolineras, restaurantes, tiendas y baños que se \\
encuentran dentro de la RCCH \\
Belleza paisajística de RCCH & 39 \\
Precios & 22 \\
Visitas guiadas & 16 \\
Diversión nocturna & 20 \\
\hline
\end{tabular}

Finalmente, el grado de satisfacción general que el turista obtuvo por la visita a la RCCH, la cual ofrece el estado de Tabasco es la siguiente. 
Cuadro 3. Grado de satisfacción del turista por la visita a la RCCH

\begin{tabular}{l|c} 
Rubro & Porcentaje \\
Satisfecho & 71 \\
Totalmente satisfecho & 24 \\
Poco satisfecho & 4 \\
Nada satisfecho & 1 \\
\hline
\end{tabular}

\section{Análisis del nivel de satisfacción de los turistas}

Dentro de las características a evaluar, se encuentra que más de $70 \%$ de los visitantes que llegan a visitar la Rcch son nacionales y el resto son extranjeros, en su mayoría norteamericanos; consideramos que esta ruta podría tener un impacto internacional debido a la importancia que tiene hoy en día el producto final "El chocolate” en sus diferentes presentaciones, por lo que es necesario no tan sólo difundir publicidad a través de medios de comunicación locales y nacionales, sino también promocionar la ruta internacionalmente, y darla a conocer a través de agencias de viajes internacionales. En su mayoría, los turistas que llegan a la ruta son estudiantes, seguidos de profesionistas; es importante difundir la existencia de nuestro destino turístico a otros segmentos como personas jubiladas ofreciéndoles actividades adecuadas. La mayoría de los turistas deciden quedarse hospedados en hoteles; sin embargo, solamente alrededor de $24 \%$ se va totalmente satisfecho con las instalaciones y el servicio ofertado durante su estancia, por lo cual debemos poner énfasis en esto y mejorar la infraestructura de los hoteles de acuerdo con el segmento al que va dirigido, y podemos destacar que contamos con una extensa gama de hoteles, pero no llegamos ni a $10 \%$ con hoteles de 4 y 5 estrellas. Si deseamos traer al turismo internacional para que vengan a apreciar nuestro destino también debemos ofertarles hoteles de mejor infraestructura y calidad en el servicio, de forma que al visitarnos su perspectiva no sólo sea buena, sino excelente. El turista que llega a la $\mathrm{RCCH}$, en su mayoría viene motivado por vivir nuevas experiencias y lugares, al igual que por descanso. El medio principal por el cual la mayoría de los turistas se enteran del destino es por medio de comentarios de amigos o familiares, por 
lo cual, podemos determinar que el medio publicitario no es la principal forma por la cual es conocida la Ruta del Cacao al Chocolate.

Podemos denotar que de acuerdo con el análisis realizado, alrededor de $30 \%$ de los visitantes se van totalmente satisfechos por los servicios ofertados y los atractivos turísticos de la ruta, sin embargo es un porcentaje bajo para posicionar la zona en el mercado turístico internacional; es necesario comentar que alrededor de $50 \%$ de los visitantes se van satisfechos; sin embargo, sabemos que para regresar a un destino turístico y recomendarlo como excelente, se requiere que los turistas evalúen su estancia con el valor totalmente satisfecho. Cabe mencionar que los turistas no se van totalmente satisfechos con las explicaciones que se les proporcionan en las visitas guiadas, por lo cual, un factor muy importante es la capacitación de estas personas y verificar y evaluar que la información que estén proporcionando los guía turísticos sea verídica. Se recomienda que se certifiquen como guías de turistas. De la misma forma podemos darnos cuenta a través de la tabla de totalmente satisfechos que otro foco rojo es en las actividades de animación y recreación que se ofertan en la ruta y la calidad con la que se brindan. En cuanto a la señalización de la zona, casi $40 \%$ de los turistas no están satisfechos. Finalmente, la mayoría están muy satisfechos de la belleza paisajística de la Ruta del Cacao al Chocolate.

\section{Análisis de la oferta}

Cuadro 4. Establecimientos hoteleros

\begin{tabular}{lcc} 
Municipios & Establecimientos & Habitaciones \\
Comalcalco & 29 & 490 \\
Cunduacán & 2 & 17 \\
Jalpa de Méndez & 0 & 0 \\
Nacajuca & 1 & 18 \\
Paraíso & 30 & 738 \\
\hline
\end{tabular}

Fuente: INEGI, 2010. 
Cuadro 5. Establecimientos de alimentos y bebidas

$\begin{array}{lccccc}\text { Municipios } & \text { Restaurantes } & \begin{array}{c}\text { Restaurantes } \\ \text { bares }\end{array} & \text { Cafeterías } & \text { Discotecas } & \text { Bares } \\ \text { Comalcalco } & 29 & 7 & 2 & 2 & 3 \\ \text { Cunduacán } & 10 & 8 & 0 & 1 & 0 \\ \text { Jalpa de } & 19 & 13 & 5 & 0 & 0 \\ \text { Méndez } & 71 & 51 & 16 & 1 & 0 \\ \text { Nacajuca } & 129 & 85 & 29 & 3 & 6 \\ \text { Paraíso } & & & & \end{array}$

Fuente: INEGI, 2010.

Cuadro 6. Otros servicios

\begin{tabular}{lccc} 
Municipios & Agencias de viajes & Balnearios & Arrendadoras de autos \\
Comalcalco & 2 & $\circ$ & 0 \\
Cunduacán & 0 & 0 & 0 \\
Jalpa de Méndez & 0 & 1 & 0 \\
Nacajuca & 0 & 0 & 0 \\
Paraíso & 1 & 2 & 1 \\
\hline
\end{tabular}

Fuente: INEGI, 2010. 
Cuadro 7. Análisis de la competencia de la ruta del cacao al chocolate.

\begin{tabular}{|c|c|c|c|c|}
\hline Yucatán & Campeche & Veracruz & Chiapas & Tabasco \\
\hline $\begin{array}{l}\text { LA RUTA DE LAS } \\
\text { HACIENDAS }\end{array}$ & $\begin{array}{l}\text { RUTA CON SENTIDO } \\
\text { COLONIAL Y ECO- } \\
\text { ARQUEOLÓGICO }\end{array}$ & $\begin{array}{l}\text { La RuTA DEL } \\
\text { CAFÉ }\end{array}$ & La Ruta del CaFÉ & $\begin{array}{l}\text { La Ruta del CaCaO al } \\
\text { ChOCOlate }\end{array}$ \\
\hline
\end{tabular}

\section{Infraestructura}

Rutas carreteras con buena pavimentación, señalética adecuada, aeropuerto internacional, puerto marítimo, agua potable, alcantarillado.
Rutas carreteras con buena pavimentación, señalética adecuada, aeropuerto internacional, puerto marítimo, variedad de establecimientos turísticos, agua potable.
Malas condiciones en rutas de acceso, poca señalética, aeropuerto internacional, puerto Dos Bocas, agua potable, variedad de establecimientos turísticos.

\section{Hospedaje}

Algunas

haciendas de Yucatán funcionan como hoteles de gran turismo
Cuenta con una gran diversidad de hoteles a elegir: gran turismo, 5, 4 estrellas, hoteles en haciendas.

\section{Hoteles 5} estrellas y gran turismo.
Servicios Resort y 5 estrellas, en las fincas cafetaleras, cabañas estilo europeo.
Sólo 5\% de los establecimientos de hospedaje son de 405 estrellas.

\section{Variedad de productos}

\begin{tabular}{|c|c|c|c|c|}
\hline $\begin{array}{l}\text { Recorridos por } \\
\text { las haciendas } \\
\text { de henequén, } \\
\text { spa, visitas a } \\
\text { un cenote, } \\
\text { áreas de juegos } \\
\text { rústicos, sitios } \\
\text { para acampar, } \\
\text { museos, } \\
\text { zoológico, } \\
\text { lienzo charro, }\end{array}$ & $\begin{array}{l}\text { Museos, casa de } \\
\text { artesanías, iglesias, } \\
\text { jardín botánico, } \\
\text { variedad de } \\
\text { restaurantes, zonas } \\
\text { arqueológicas, } \\
\text { grutas, } \\
\text { representación del } \\
\text { juego de pelota, } \\
\text { haciendas, }\end{array}$ & $\begin{array}{l}\text { Recorrido por } \\
\text { la fábrica de } \\
\text { café Museo } \\
\text { del Café, } \\
\text { senderismo, } \\
\text { apreciación } \\
\text { del proceso } \\
\text { del café, } \\
\text { degustación de } \\
\text { café. Talleres } \\
\text { ambientales. }\end{array}$ & $\begin{array}{l}\text { Fincas cafetaleras, } \\
\text { actividades de } \\
\text { agroturismo, } \\
\text { ecoturismo, deportes } \\
\text { extremos, senderismo, } \\
\text { recorridos entre la } \\
\text { selva, paseos a caballo, } \\
\text { apreciación del proceso } \\
\text { del café, floricultura. }\end{array}$ & $\begin{array}{l}\text { Se encuentran } \\
\text { haciendas, playas, zona } \\
\text { arqueológica, corredor } \\
\text { turístico, museo del } \\
\text { chocolate, iglesias, } \\
\text { pueblos chontales } \\
\text { mayas, apreciación del } \\
\text { proceso del chocolate. }\end{array}$ \\
\hline
\end{tabular}

representación

de bailes

autóctonos. 
Cuadro 7. Análisis de la competencia de la ruta del cacao al chocolate.

(finaliza)

\section{Promoción}

Promoción de sus productos en diferentes medios de publicidad como: TV, agencias de viajes, página web del estado de Yucatán, páginas webs de promoción turística y hoteles.
Promoción de sus productos en diferentes medios de publicidad como: agencias de viajes, página web del estado de Tabasco, páginas web de promoción turística

Fuente: Trabajo de campo.

\section{Análisis FODA}

Se procedió a la elaboración de un análisis FoDA con el fin de evaluar cada una de las fortalezas y las oportunidades con las que cuenta la RCCH para aprovecharlas y convertirlas en fortalezas, así como las debilidades y amenazas para convertirlas en oportunidades, y asimismo proponer estrategias con el fin de mejorar la ruta. 
Cuadro 8. Fortalezas y debilidades de la RCCH

\section{Fortalezas}

Diversificación de actividades turísticas

Plantaciones de cacao

Tierra fértil para la producción de cacao

Diversidad de turismo gastronómico

Posicionamiento como las mejores playas del estado( Paraíso)

Variedad de establecimientos hoteleros

Variedad de establecimientos restauranteros
Debilidades

Desaprovechamiento de tierra fértil

Deterioro de las fincas o haciendas cacaoteras

Falta de publicidad para establecimientos restauranteros

No existe web oficial de la ruta del cacao

Sólo $5 \%$ de establecimientos hoteleros son de 4 y 5 estrellas

Existen municipios pobres en variedad de establecimientos gastronómicos

Infraestructura en decadencia( la mayoría de restaurantes)

Poca publicidad en beneficio a atractivos turísticos

Falta de cultura de anfitriona

\begin{tabular}{ll}
\hline \multicolumn{1}{c}{ Cuadro 9. Oportunidades y amenazas de la RCCH } \\
\multicolumn{1}{c}{ Oportunidades } & \multicolumn{1}{c}{ Amenazas } \\
Turismo experimental & Peligro de extinción en plantaciones de cacao \\
$\begin{array}{l}\text { Implementar sitios de interacción con } \\
\text { enfoque al cacao y chocolate }\end{array}$ & Estado vecino cuenta con la misma \\
Promover sitios turísticos como los humedales & Yucatán cuenta actualmente con un \\
Pomposú-Juliva, Granja de tortugas & Eco-museo del Cacao \\
Promover afluencia de turismo, & Franquicias extranjeras se establecen en \\
aprovechando que es la ruta más conocida & los municipios de la ruta \\
en el estado & \\
Mayor oferta y demanda de & Estados vecinos promueven su oferta \\
establecimientos restauranteros & turística de manera fluida a través de \\
& $\begin{array}{l}\text { la publicidad en diferentes medios } \\
\text { de comunicación, ofertando destinos }\end{array}$ \\
& parecidos a los que contamos. \\
& Seguridad \\
\hline
\end{tabular}



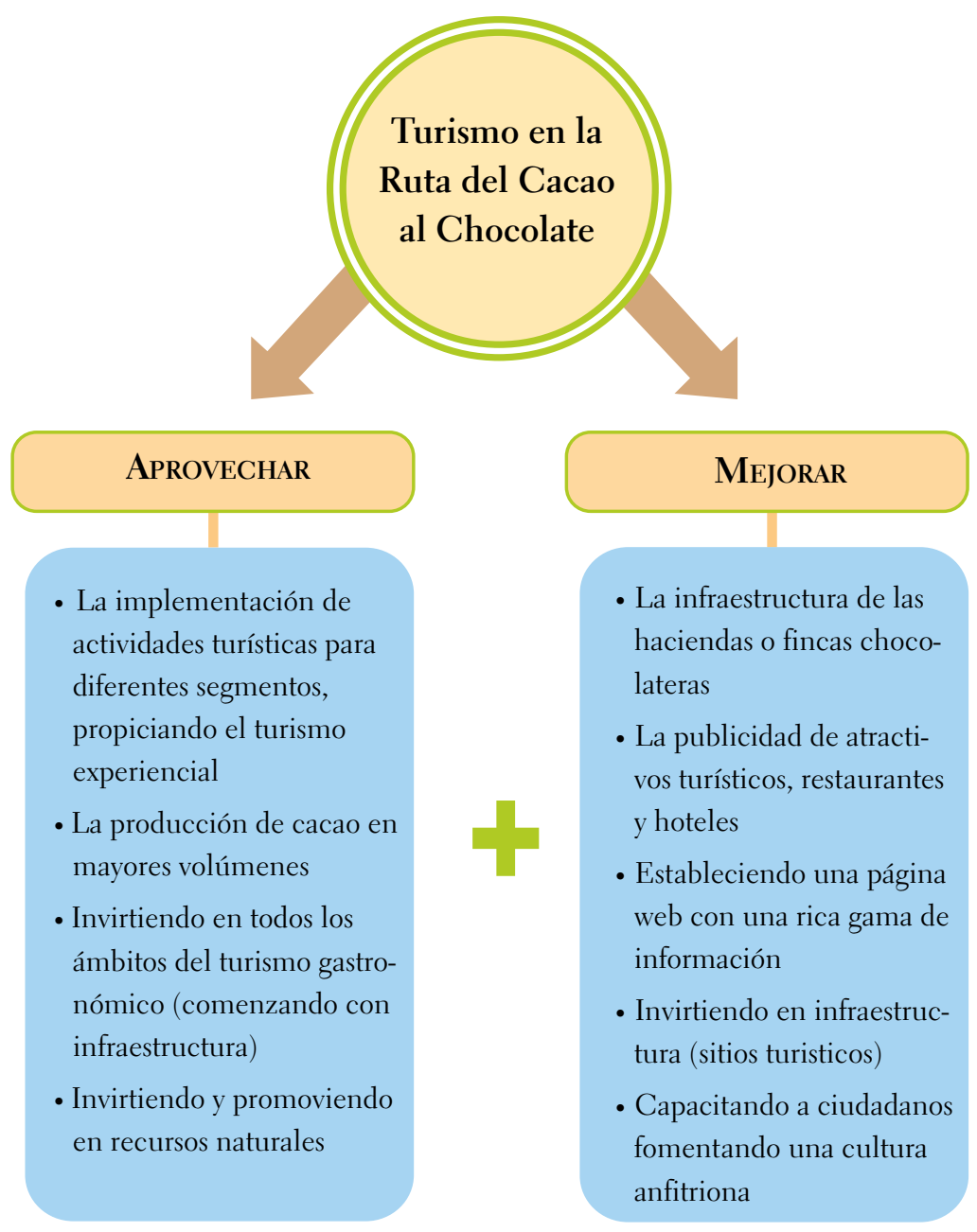

Figura 1l. Esquema de Análisis de la ruta del cacao al chocolate

\section{Etapa 3. Elaboración del plan de mercadotecnia}

\section{Productos turísticos}

A partir del trabajo realizado en las etapas anteriores, se procedió a seleccionar los recursos turísticos estratégicos sobre los que se basaría el plan de mercado- 
tecnia de la Rcch, así como la oferta turística que cumpliera con los requerimientos de calidad solicitados por los turistas (véanse la figura 12 y el cuadro 10).

$$
\text { OFERTA }=\text { RECURSOS }+ \text { SERVICIOS }+ \text { EQUIPAMIENTO }+ \text { INFRAESTRUCTURAS }
$$
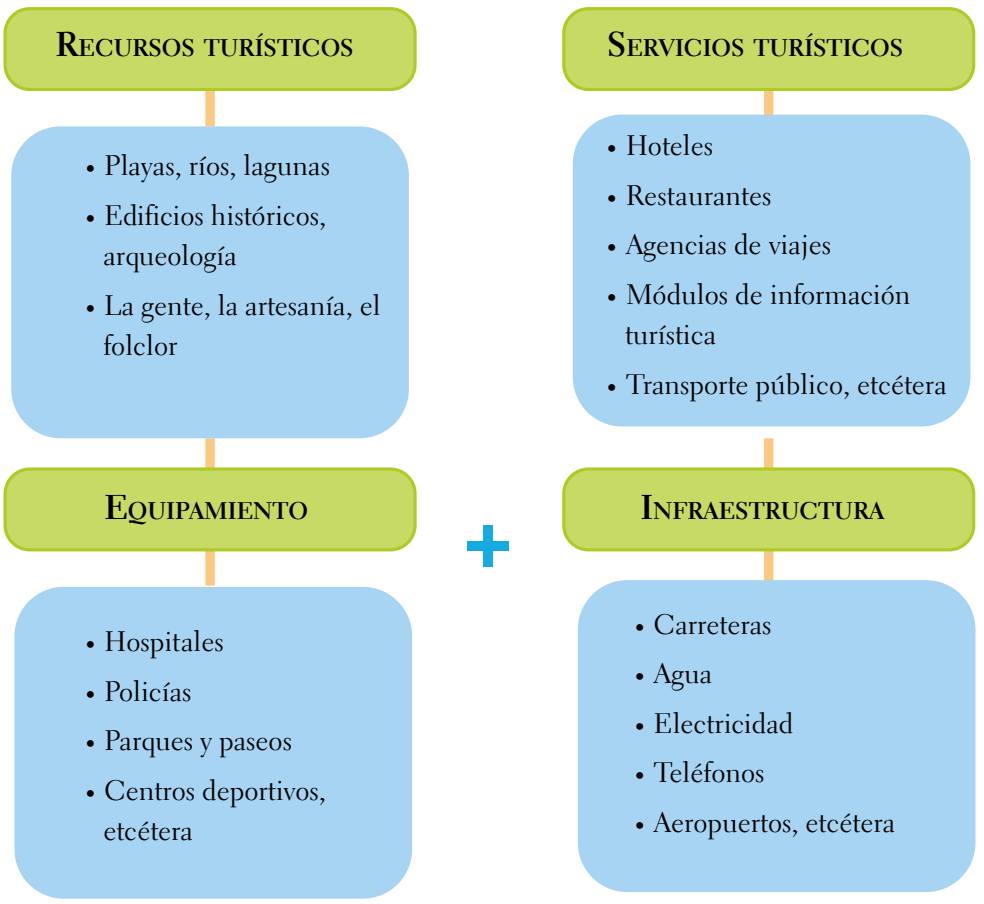

TIPO DE RECURSOS TURÍSTICOS
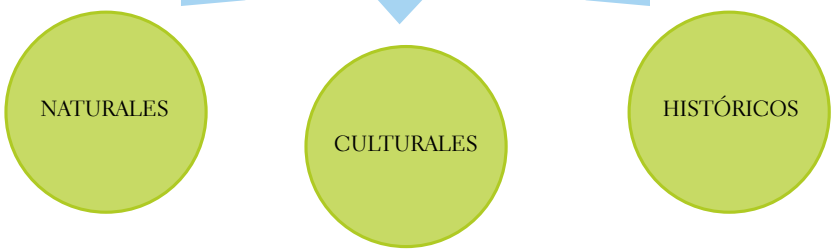

Figura 12. Recursos estratégicos y oferta turística para el plan de mercadotecnia de la RCCH 
Cuadro 10. Ejemplo de producto turístico.

Recorrido por las haciendas chocolateras

Recursos y equipamiento de apoyo

Paisaje: vegetación donde se toma una rica tropical y aromática aventura.

Arquitectura local: casas con arquitectura rústica y moderna.

Gastronomía: tamalitos de chipilín de masa colada, de cabeza de puerco, maneas, chanchamitos, tostadas, enchiladas, panuchos, empanadas, carnitas, barbacoa, cecina, asado de res y cerdo.

Artesanía/productos típicos: en el pueblo de Cupilco se elaboran objetos de cerámica.

\section{ACTIVIDADES}

- Explicaciones del crecimiento del cacao

- Explicación de cómo se hace el injerto de la planta del cacao criollo

- Recorrido por las plantaciones

- Explicación de las características del cacao: su resistencia al clima, la cosecha y cómo combaten las plagas de manera orgánica, sin pesticidas

- Recorrido por lo que eran las antiguas y típicas haciendas chocolateras de principios de siglo xx

- Hacer una muestra de como funcionaban las maquinas rusticas utilizadas para separar granos de cacao, los elementos de una cocina chontal(etnia indígena de la región) y de sus vestimentas típicas

- Paseo por la fábrica de chocolate

- Observación de las maquinarias industriales que son utilizadas para secar y moler las semillas de cacao

- Visita a una enorme vianda de chocolates blancos, negros, amargos, dulces, con avellana, leche, cacahuate, entre otros

\section{LA UTILIDAD DE LA EXPERIENCIA PARA EL TURISTA}

- El disfrute de un paisaje único y apasionante

- El contacto con las plantaciones de Cacao

- Sentir el contacto con la naturaleza virgen y apreciar su belleza

- Probar la variedad de chocolates que se fabrican 


\section{Estrategias turísticas}

Se definieron las estrategias a corto, mediano y largo plazo, con el fin de definir cada estrategia con base en sus prioridades en el mercado, esto quiere decir que la oferta turística se ha orientado a ser auténtica, logrando atraer por sus atractivos a la demanda turística, ajustándola a las necesidades y preferencias del turista, ofertándoles una variada gama de actividades para diferentes tipos de segmentos (cuadro 11).

Cuadro 11. Estrategias para el desarrollo turístico de la RCCH

A corto plazo

A mediano plazo
- Promover la difusión de publicidad en beneficio a los sitios gastronómicos de la región, que se encuentran ubicados dentro de la ruta

- Promover la conservación de las áreas naturales de la Ruta del Cacao al Chocolate mediante la actividad turística

- Fomentar el desarrollo de una cultura de anfitriona, información, seguridad y calidad ambiental

- Mejorar la seguridad de los turistas en los destinos de Tabasco

- Dar a conocer a los productores de cacao la importancia que tienen a nivel nacional e internacional, e impulsarlos a fortalecer sus haciendas y fincas, promoviendo la ayuda de parte de diversas instituciones que estén dispuestas a invertir, con el fin de establecer un mercado potencial en la ruta

- Crear una página web oficial de la Ruta del Cacao al Chocolate, manteniéndola al día de los datos más importantes e interesantes, de igual forma crear enlaces para promover cada uno de los establecimientos restauranteros, hoteleros, transportadoras y agencias de viajes con el fin de que el turista pueda tener al alcance todos los recursos sin tener complicaciones para visitar la ruta

- Suscitar a los ciudadanos a invertir y enriquecer los municipios de Cunduacán y Jalpa de Méndez para tener una amplia gama de establecimientos gastronómicos, ayudándolos en la publicidad a través de redes sociales 
Cuadro 11. Estrategias para el desarrollo turístico de la RCCH

(finaliza)

\begin{abstract}
A mediano plazo
- Reforzar al desarrollo de una cultura de anfitriona, información, seguridad y calidad ambiental

- Impulsar la práctica del turismo experiencial, a través del proceso que lleva el cacao para convertirlo en chocolate

A largo plazo

- Impulsar a los establecimientos de alojamiento, a buscar una mejora continua en su infraestructura, de igual forma proporcionar capacitaciones a los trabajadores de dichos establecimientos (Coordinación de Turismo del Estado de Tabasco, otorga capacitaciones, con previo aviso).

- Implementar un parque-museo interactivo, que permita al visitante conocer desde nuestra cultura hasta la forma en que se produce el cacao hasta la elaboración del chocolate
\end{abstract}

\title{
Fijación de objetivos
}

Es necesario plantear perfectamente los objetivos de la Ruta del Cacao al Chocolate para establecer una campaña publicitaria basada en necesidades específicas.

- Dar a conocer al público objetivo las novedades de la ruta

- Atraer nuevos clientes hacia los puntos de venta, empezando por los nacionales y posteriormente con los extranjeros

- Alcanzar a consumidores potenciales

- Vender la imagen de la ruta turística

- Fomentar el recuerdo del producto y servicio ofertado

\section{Realización del briefing}

- Definición del público objetivo: turistas nacionales e internacionales

- Definición del producto: Ruta del Cacao al Chocolate 
- Características y condiciones del mercado potencial: actualmente la Ruta del Cacao al Chocolate se encuentra con buena afluencia turística en temporadas altas, sin embargo es necesario lanzar una campaña de publicidad constante para mantener una excelente afluencia de turismo en todo el año

- Entorno competitivo: estado vecino Chiapas y Yucatán

- Indicación de los canales: agencias de viajes, hoteles, Secretaría de Turismo Federal y Coordinación de Turismo del Estado.

- Experiencias y análisis histórico-publicitarios: han existido campañas publicitarias realizadas por la Coordinación de Turismo, sin embargo no han sido permanentes y constantes, se ha dado a conocer a través de páginas de internet (http://www.visitmexico.com/es/haciendas-decacao-en-tabasco/) de la Secretaría Federal, pero no ha llegado a más; actualmente no hay difusión en medios de comunicación en el estado de Tabasco, sólo se ha podido posicionar levemente en el mercado a través de los últimos años con el Festival del Chocolate realizado en la capital del estado.

- Objetivos que deseamos cumplir: mejorar la imagen de la ruta, promoviendo cada uno de sus atractivos, posicionarlos en la mente de los turistas nacionales y después con turistas extranjeros.

\section{Propuesta base}

El plan de mercadotecnia tiene como estrategias la implementación de mensajes publicitarios a través de medios masivos de comunicación como radio, televisión, e Internet, en donde se reúne una gran diversidad de público de todas las edades y clases sociales, así como a través de carteles y folletos. Además se utilizarán abanicos, lapiceros y otros souvenirs con la publicidad impresa, los cuales se ofertarán en agencias de viajes, central de autobuses, aeropuertos e incluso otros destinos turísticos relacionados con la ruta. 


\section{Importancia del plan de medios}

\section{¿Qué es lo que la Ruta del Cacao al Chocolate pretende alcanzar?}

1. Potenciar la demanda turística, utilizando un sitio web para dar a conocer la RCcH y los atractivos con los que cuenta y comercializarla

2. Realzar la imagen de la RCCH

3. Beneficiar al estado y primordialmente a los municipios que conforman la RCCH, dejando una mayor derrama económica y contribuir al desarrollo de los ciudadanos

¿Por qué es importante un plan de medios para la exhibición?

Es necesario que la RccH sea promocionada a través de un sitio web específico, dedicado a dar difusión a cada uno de los atractivos turísticos de la región, así como a establecimientos restauranteros, hoteleros, medios de transporte, agencias de viajes entre muchos más con el fin de ofertar la RccH en conjunto y darla a conocer para consolidar segmentos de turistas que lleguen continuamente.
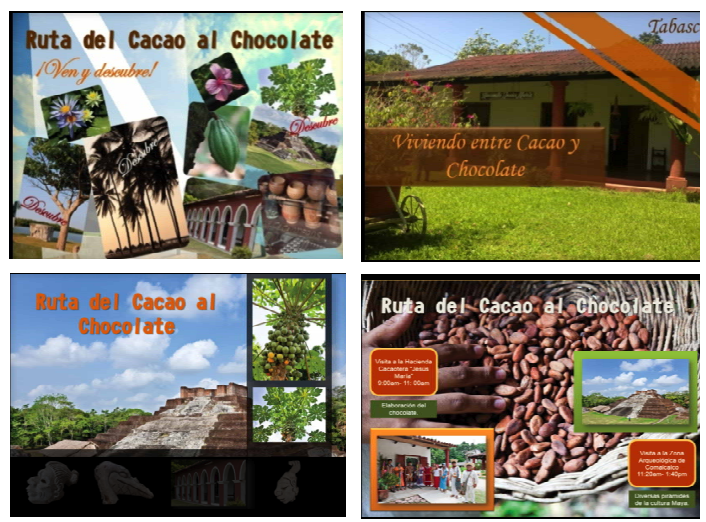

Figura 13. Diseño de folletos y carteles 


\section{Conclusión}

De acuerdo con los recorridos realizados por los diversos municipios integrantes de la Ruta del Cacao al Chocolate y del levantamiento del inventario turístico, se encontró que los atractivos turísticos de la ruta se centran en las categorías 1,2 y 3 , es decir, recursos naturales (costas, lagunas, ríos), museos y manifestaciones culturales (museos, zonas arqueológicas) y folclor (manifestaciones religiosas, música y danza, artesanías, grupos étnicos). Por otra parte, la mayoría de los recursos se encuentran dentro de la jerarquía 2 y 3 de grado de atracción de los recursos turísticos. La evaluación al patrimonio turístico de la ruta del cacao al chocolate nos permitió obtener una valoración de 65 puntos. Los sitios de valor patrimonial más visitados por los turistas en la $\mathrm{RCCH}$, de acuerdo con una encuesta aplicada en julio-agosto 2012, fue la zona arqueológica de Comalcalco, las haciendas cacaoteras y el corredor turístico Puerto Ceiba-Chiltepec.

El municipio de Comalcalco cuenta con una zona arqueológica peculiar y de suma importancia para el país, una de sus características es la preservación de sus elementos arqueológicos como la arquitectura, por lo tanto eso puede ayudar a impulsar el turismo como lo han hecho otros estados en determinadas temporadas con mayor auge. De igual forma en las haciendas cacaoteras con las que cuenta, el visitante puede realizar paseos turísticos y visualizar el trabajo y la producción del cacao para la elaboración del chocolate además de degustarlo.

Paraíso cuenta con diferentes atractivos comenzando por sus hermosas playas. Se ha invertido en infraestructura y la recepción de turistas ha aumentado, sin embargo también tiene un gran mercado en el ámbito restaurantero al igual que Nacajuca con su corredor gastronómico BijiYokot'an, que en la actualidad se está trabajando con la mayoría de las empresas, otorgándoles de manera gratuita asesoramientos a través del Programa Apadrinamiento 2013, que está llevando a cabo la Coordinación de Turismo del Estado de Tabasco junto con estudiantes a punto de egresar de carreras relacionadas con Turismo, Gastronomía y Diseño. 
Cunduacán y Jalpa de Méndez son municipios con menor demanda turística en la Ruta del Cacao al Chocolate, sin embargo, cuenta con una diversidad de recursos naturales y culturales; pero es necesaria la organización entre productores de cacao del municipio de Cunduacán y productores de Comalcalco para establecer una mayor productividad y lograr un mejor posicionamiento en el mercado a nivel nacional e internacional. De acuerdo con el análisis realizado podemos llegar a la conclusión de que la Ruta del Cacao al Chocolate cuenta con una amplia gama de atractivos que pueden fructificar, ya que por diferentes motivos no se han aprovechado al máximo en materia de turismo.

\section{Comentario final}

Primordialmente, se debe capacitar a los prestadores de servicios hoteleros, restauranteros, y cada uno de los sitios turísticos, con el fin de brindar un mejor servicio a los turistas que visiten la Ruta. De igual forma, es importante dar pláticas a las comunidades que tienen un contacto más cercano con el turista, inculcándoles que todos serán beneficiados, incluso determinar un concepto como "No existe turismo de calidad, sin personas de calidad"; se requiere del desarrollo de una cultura turística que permita correlacionar adecuadamente a los turistas con las comunidades receptoras. Es indispensable hacer uso de la publicidad en conjunto para todos los sitios turísticos que se encuentran ubicados dentro de la ruta del cacao al chocolate para la obtención de beneficios comerciales. Crear un sitio de página web oficial de la Ruta del Cacao al Chocolate, manteniéndola al día, detallando informes de relevancia con respecto al cacao y el proceso de producción del chocolate, sobre eventos como el Festival del Chocolate y, finalmente, para promover cada uno de los establecimientos restauranteros, hoteleros, transportadoras y agencias de viajes con el fin de que el turista pueda tener al alcance toda la información necesaria sin complicaciones para visitar la ruta del cacao al chocolate. 


\section{Literatura consultada}

Acerenza, M. (2006). Conceptualización, origen y evolución del turismo. México: Trillas.

Azcona, O. (2011). Patrimonio cultural y natural de los tabasqueños. México: Secretaría de Educación Pública.

Boullón, R. Molina S. y Rodríguez M. (1983) Un nuevo tiempo libre. México: Trillas.

Cárdenas, F. (1999). Mercadotecnia y productividad turística. México: Trillas.

Cárdenas, F. (1997). La segmentación del mercado turístico. México: Trillas.

Cárdenas, F. (1986). Producto turístico: Aplicación de la estadistica y del muestreo para su diseño (2 ${ }^{\mathrm{a}}$. ed.), México: Trillas.

Cárdenas, F. (2006)Proyectos turísticos: localización e inversión (2 ${ }^{\text {a }}$. ed.). México: Trillas.

Casasola, L. (1990). Turismo y ambiente. México: Trillas.

De la Torre, O. (1980). Turismo fenómeno social. México: Trillas.

Elías, L. (2009). Otras formas de turismo. México: Trillas.

Eyssautier, M. (1995). Elementos básicos de mercadotecnia. México: Trillas.

Fisher, L. Espejo, G. (2004.) Mercadotecnia (3a ed.). México: McGraw Hill.

Gallegos, M. (2001). Iglesias polícromas de la Chontalpa, Tabasco. Instituto Nacional de Antropología e Historia.

García, O. (2004). Historia y geografía del estado de Tabasco (4ª ed). México: Secretaría de Educación Pública.

Goeldner, R. (2011). Turismo: Planeación, administración y perspectivas $\left(3^{\mathrm{a}}\right.$. ed.). México: Limusa.

Hernández, E. (2005). Planificación turística: un enfoque metodológico. México: Trillas.

Kotler, P., Bowen, J. y Makens J. (2004). Marketing para turismo ( $3^{\text {a }}$ ed.). Madrid: Pearson Educación.

Kotler, P., Keller y Kevin (2012). Dirección de marketing. México: Pearson.

León, M., Lizama F. (2012). Trabajo de titulación de T.S.U. "Evaluación del nivel de satisfacción percibida por los turistas a partir de variables de valo- 
ración de la visita a los atractivos turísticos que conforman la Ruta del Cacao al Chocolate".

Molina, S. (1998). Turismo y ecología (7a . ed.). México: Trillas.

Sánchez, J.(2007). Tesoros turísticos de México. México: Trillas.

Sectur. (2004). Guía Oficial de Destinos para el Turismo de Aventura, Ecoturismo y Turismo Rural en México, México.

Torruco, M. (1999). La industria de la esperanza (2 ${ }^{\text {a }}$. ed.). México: Grupo Editorial Quinto Centenario.

Zamorano, F. (2007). Turismo alternativo: servicios turísticos diferenciados $\left(2^{\mathrm{a}}\right.$ ed.). México: Trillas.

$32^{\mathrm{a}}$. Conferencia General. UNESCO (2003) 